\title{
Accuracy in the Assessment of Damages
}

\section{Citation}

Louis Kaplow and Steven Shavell, Accuracy in the Assessment of Damages, 39 J. L. Econ. 191 (1996).

\section{Published Version}

http://www.jstor.org/stable/725773

\section{Permanent link}

http://nrs.harvard.edu/urn-3:HUL.InstRepos:10611796

\section{Terms of Use}

This article was downloaded from Harvard University's DASH repository, and is made available under the terms and conditions applicable to Other Posted Material, as set forth at http:// nrs.harvard.edu/urn-3:HUL.InstRepos:dash.current.terms-of-use\#LAA

\section{Share Your Story}

The Harvard community has made this article openly available.

Please share how this access benefits you. Submit a story.

Accessibility 


\section{CHICAGO JOURNALS}

Accuracy in the Assessment of Damages

Author(s): Louis Kaplow and Steven Shavell

Source: Journal of Law and Economics, Vol. 39, No. 1 (Apr., 1996), pp. 191-210

Published by: The University of Chicago Press

Stable URL: http://www.jstor.org/stable/725773

Accessed: 16/02/2010 20:07

Your use of the JSTOR archive indicates your acceptance of JSTOR's Terms and Conditions of Use, available at http://www.jstor.org/page/info/about/policies/terms.jsp. JSTOR's Terms and Conditions of Use provides, in part, that unless you have obtained prior permission, you may not download an entire issue of a journal or multiple copies of articles, and you may use content in the JSTOR archive only for your personal, non-commercial use.

Please contact the publisher regarding any further use of this work. Publisher contact information may be obtained at http://www.jstor.org/action/showPublisher?publisherCode=ucpress.

Each copy of any part of a JSTOR transmission must contain the same copyright notice that appears on the screen or printed page of such transmission.

JSTOR is a not-for-profit service that helps scholars, researchers, and students discover, use, and build upon a wide range of content in a trusted digital archive. We use information technology and tools to increase productivity and facilitate new forms of scholarship. For more information about JSTOR, please contact support@jstor.org.

The University of Chicago Press is collaborating with JSTOR to digitize, preserve and extend access to Journal of Law and Economics. 


\title{
ACCURACY IN THE ASSESSMENT OF DAMAGES*
}

\author{
LOUIS KAPLOW and STEVEN SHAVELL \\ Harvard Law School and National Bureau of Economic Research
}

\begin{abstract}
Assessment of damages is a principal issue in litigation and, in light of this, we consider the social justification for, and the private benefits of, accurate measurement of harm. Greater accuracy induces injurers to exercise levels of precaution that better reflect the magnitude of the harm they are likely to generate, and, relatedly, it stimulates uninformed injurers to learn about risks before acting. However, accuracy in assessment of harm cannot influence the behavior of injurers - and is therefore of no social value - to the degree that they lack knowledge of the harm they might cause when deciding on their precautions. Regardless of the social value of accuracy, litigants generally gain by devoting resources toward proof of damages, leading often to socially excessive private incentives to establish damages.
\end{abstract}

\section{INTRODUCTION}

A

SSESSMENT of damages is often a principal issue in litigation because the primary objective of the plaintiff usually is to collect as much as possible and that of the defendant is to pay as little as possible. Accordingly, litigants frequently devote substantial time and effort attempting to establish the level of harm. In light of this, the question naturally arises concerning the underlying social purpose of accurate determination of harm. Our object here is to address this question and to compare socially desirable effort to ascertain harm with what parties in litigation wish to expend on the task. To this end, we consider a version of the now standard model of liability for harm ${ }^{1}$ in Section II of the article, and we develop the following four points. ${ }^{2}$

* We are grateful to Marcel Kahan, the Journal's editors, and participants in seminars at Harvard and New York University Law Schools for helpful comments, and for research support from the John M. Olin Center for Law, Economics, and Business at Harvard Law School. Shavell also acknowledges aid from the National Science Foundation (grant no. SES-911-1947).

${ }^{1}$ See, for exan $\rightarrow$, John P. Brown, Toward an Economic Theory of Liability, 2 J. Legal Stud. 323 (1973); William M. Landes \& Richard A. Posner, The Economic Structure of Tort Law (1987); and Steven Shavell, Economic Analysis of Accident Law (1987).

${ }^{2}$ As will be seen, the emphasis in this article is on the points that assessment of damages is not socially worthwhile if parties do not know the magnitude of harm when they act and that, despite this, parties may have strong incentives to spend to determine damages in court. These points have not been developed elsewhere to our knowledge, although Louis

[Journal of Law and Economics, vol. XXXIX (April 1996)]

(C) 1996 by The University of Chicago. All rights reserved. 0022-2186/96/3901-0006 $\$ 01.50$ 
First, accuracy in the assessment of harm leads potential injurers to act in a way that reflects the magnitude of the harm they might cause-to take greater precautions the greater the harm they are likely to bring about. This fundamental and familiar point is the social justification for accurate assessment of damages in the model. ${ }^{3}$

Second, accuracy in the assessment of harm cannot influence the behavior of injurers-and is therefore of no social value-to the degree that they lack knowledge of the level of harm they might cause when they make their decisions. Thus, if, when choosing his precautions, an injurer knows only that the average level of harm that would be caused in an accident is $\$ 500,000$, there is no point in the court's measuring harm accurately. As long as the injurer's expected liability is $\$ 500,000$, his behavior will be the same as if harm were measured precisely.

Third, accuracy in assessing harm may spur injurers to learn more before they act about the harm they might cause, for then they can benefit by altering their level of precautions. They will have no motive to learn about the level of harm in advance if damages will be based on average harm, for then the particular level of harm will not affect their damage payments. That injurers have an incentive to learn about harm before they act may of course be socially beneficial because it is desirable for the level of precautions to reflect the magnitude of the potential harm.

Fourth, litigants' incentives to provide information about harm to courts may be socially excessive. Defendants will want to establish the true level of harm if it is less than estimated harm, and plaintiffs will want to demonstrate the true harm if it exceeds the estimated level. But these incentives to establish harm exist independently of the social value,

Kaplow, A Model of the Optimal Complexity of Legal Rules, 11 J. L., Econ., \& Org. 150 (1995), deals with closely related issues in analyzing which variables courts optimally ought to include in legal rules. In addition, for an informal discussion that expands on the one in the present paper, $\rightarrow$ Louis Kaplow, The Values of Accuracy in Adjudication: An Economic Analysis, 23 J. Legal Stud. 307 (1994). There are, in addition, a number of articles on the subject of accuracy concerning issues different from those addressed in this article, including Richard Craswell \& John Calfee, Deterrence and Uncertain Legal Standards, 2 J. L., Econ., \& Org. 279 (1986) (on mistake in assessing negligen $\rightarrow$ Louis Kaplow \& Steven Shavell, Accuracy in the Determination of Liability, 37 J. Law \& Econ. 1 (1994); Ivan Png, Optimal Subsidies and Damages in the Presence of Judicial Error, 6 Int'l Rev. L. \& Econ. 101 (1986); A. Mitchell Polinsky \& Steven Shavell, Legal Error, Litigation, and the Incentive to Obey the Law, 5 J. L., Econ., \& Org. 99 (1989); $\rightarrow$ Daniel Rubinfeld \& David Sappington, Efficient Awards and Standards of Proof in Judicial Proceedings, 18 Rand J. Econ. 308 (1987) (all on mistake in determining who committed a punishable act); $\rightarrow$ Richard Posner, An Economic Approach to Legal Procedure and Judicial Administration, 2 J. Legal Stud. 399 (1973) (a general discussion of accuracy).

${ }^{3}$ Another possible justification for accuracy is that it assures victims full compensation. We mention this issue in Section III below but note that its importance is not substantial, in part due to the presence of insurance markets. (The issue does not enter in our model because parties are assumed to be risk-neutral.) 
if any, of accurate assessment of harm. For example, the incentives exist when defendants, at the time that they act, do not know the level of harm, which is to say, when accuracy in determining harm has no effect on behavior and hence no social value. It is true as well that if defendants know or may learn the level of harm when they act, incentives to demonstrate harm may be excessive.

After analyzing these points, we consider briefly in Section III the generality of our analysis and extensions to it concerning settlement, risk aversion, the effect of injurers' behavior on the magnitude of harm, and certain aspects of information. In Section IV, we discuss the implications of our analysis-including the possible utility of restricting expenditures on ascertaining damages, and also the use of tabular damages-in some typical settings of adjudication.

\section{AnAlysis}

Assume that risk-neutral injurers choose levels of precaution $x$ to reduce the risk $p(x)$ of accidents, where $0<p(x)<1, p^{\prime}(x)<0$, and $p^{\prime \prime}(x)>0$. A particular injurer will cause one particular level of harm $h$ if involved in an accident, but different injurers cause different levels of harm. Let $f(h)$ be the density of $h$ on $[0, \infty)$, where $f(h)>0$. Injurers and courts are presumed to know the density $f$. (This assumption can be reinterpreted and relaxed, without affecting our results; see Sections III $e$ and III $f$ below.)

If an accident occurs, the injurer who caused it will be held strictly liable and will be required to pay damages $d$ in court (on the possibility of settlement, see, as noted, Section III $b$ below). Assume also that there is a cost $k$ to an injurer of presenting information about harm to courts. ${ }^{4}$ In addition, in one version of the model, we will assume that there is a cost $c$ to an injurer of obtaining information about harm before he chooses his precautions.

Social costs exclusive of the expense of obtaining or presenting information about $h$ are

$$
\int_{0}^{\infty}[x(h)+p(x(h)) h] f(h) d h,
$$

where $x(h)$ denotes the precautions taken by injurers who would cause losses of $h$. The social goal is to minimize the sum of the foregoing expression and any relevant expenses of obtaining and presenting information about $h$. Let $x^{*}(h)$ denote the $x$ that minimizes $x+p(x) h$.

\footnotetext{
${ }^{4}$ The assumption that $k$ is borne by injurers rather than by courts is, for the most part, inessential. If $k$ is borne by courts and damages are raised by $k$ from the level we say below is optimal, our conclusions remain valid except, as will be obvious, in Section IIC below.
} 


\section{A. Ex Ante Information Is Exogenous}

We consider first the cases in which injurers do and do not know $h$ ex ante. We ask whether it is desirable for $h$ to be observed by courts, which would involve a cost $k$. Our conclusion (proved in the appendix) is:

Proposition 1. (a) Suppose that injurers do not know harm $h$ ex ante. Then it is optimal for courts not to observe $h$ and for damages to equal $\bar{h}$, expected harm. In this case, injurers will behave socially optimally given their lack of information about $h$.

(b) Suppose that injurers know harm ex ante. Then it is optimal for courts to observe $h$ and for damages to equal $h$ (rather than $\bar{h}$ ) if and only if the cost $k$ of observing $h$ is sufficiently low. If damages equal $h$, injurers will behave socially optimally.

The reason for $1(a)$ is, of course, that if injurers do not know $h$ ex ante, their behavior cannot be affected by the fact that their damage payments will depend on $h$; because social resources must be expended for damage payments to depend on $h$, this cannot be desirable. ${ }^{5}$ Furthermore, if $d=\bar{h}$, injurers will correctly take into account the expected harm caused by their activity and thus be led to take proper precautions.

The explanation for $1(b)$ is that, when injurers know $h$ ex ante and their damage payments depend on $h$, they will, desirably, choose their level of precautions in accord with $h$. Hence, if it is not too costly for $h$ to be observed by courts, that will be socially worthwhile.

\section{B. Endogenous Acquisition of Information Ex Ante}

Suppose now that injurers choose whether to acquire information ex ante by making an expenditure: initially, they do not know $h$, but if they spend $c$, they learn $h$ ex ante. In this case, the result is:

Proposition 2. Suppose that injurers can learn harm $h$ ex ante by making an expenditure $c$.

(a) If it is not socially optimal for injurers to learn $h$ ex ante, it is optimal for courts not to observe $h$ and for damages to equal $\bar{h}$. In this case, injurers will not learn $h$ and will behave optimally given their lack of information about $h$.

(b) If it is socially optimal for injurers to learn $h$ ex ante, it is optimal

${ }^{5}$ More precisely, taking as given an injurers' ex post litigation costs, we see that behavior is unaffected by whether or not damages depend on $h$. But when damages do not depend on $h$, injurers do not spend $k$ in the event of an accident. Expected liability costs are thus lower, and so will be injurers' precautions. This change in behavior, however, is efficient: the social cost of accidents is lower because resources are no longer spent determining $h$ each time there is an accident. (This is apparent in the proof in the Appendix.) 
for courts to observe $h$ and for damages to equal $h$. In this case, injurers will learn $h$ and will behave optimally. ${ }^{6}$

The result in 2(a) follows from proposition $1(a)$ and the fact that injurers will clearly have no incentive to learn $h$ ex ante when damages are $\bar{h}$. The result in $2(b)$ will follow from proposition $1(b)$ if, when damages are $h$ and it is socially optimal for injurers to learn $h$, they are in fact induced to learn $h$. We prove this in the Appendix. Essentially, the result holds because the social benefit of injurers becoming informed is internalized by injurers when damages equal $h$.

\section{Endogenous Reporting of Information Ex Post}

Suppose here that, whether or not injurers know $h$ ex ante, after accidents occur injurers (defendants) and victims (plaintiffs) know $h$ and either type of party can elect to establish $h$ to courts at cost $k$. (We assumed above that courts, not parties, decide whether or not $k$ is spent to establish $h$.) Let us first reconsider the case in which injurers do not know $h$ ex ante.

Proposition 3. Suppose that injurers do not know harm $h$ ex ante and that, after an accident, parties choose whether or not to spend $k$ to establish $h$ to courts.

(a) It is optimal for damages to equal expected harm $\bar{h}$ regardless of whether a party establishes $h$. In this case, no parties will spend to establish $h$.

(b) If instead damages equal $h$ whenever a party establishes $h$, plaintiffs and defendants will sometimes spend $k$ to establish $h$, which is inefficient.

With regard to $3(a)$, we know from proposition $1(a)$ that, when injurers do not know $h$ ex ante, setting damages equal to $\bar{h}$ will induce them to take optimal precautions given their lack of knowledge of $h$. And when damages equal $\bar{h}$, parties will obviously have no incentive to spend to establish $h$, which could only add to social costs. Moreover, with respect to $3(b)$, if damages equal $h$ whenever a party establishes $h$, defendants will spend $k$ to do this when $h+k<\bar{h}$, and plaintiffs will spend $k$ when $h-k>\bar{h}$; thus $k$ will be spent when $|h-\bar{h}|>k$.

The excessive private incentive to spend to establish $h$, described in

${ }^{6}$ This result about the desirability of accurate assessment of $h$ by courts may be compared to another beneficial effect of accuracy under assumptions different from ours. Suppose that, if courts do not accurately assess harm, parties will expend effort to predict the errors courts would make (even though the parties might know the true harm). Then accurate measurement of harm by courts would be beneficial because it would discourage parties from investing effort to predict courts' errors. On this general issue, see Louis Kaplow \& Steven Shavell, Private versus Socially Optimal Provision of Ex Ante Legal Advice, 8 J. L., Econ., \& Org. 306 (1992). 
$3(b)$, exists because, after an accident occurs, a party may well have a positive motive to spend to establish $h$ so as to alter damages in his favor. But this motive is unrelated to the incentive benefit associated with establishing $h-a$ benefit that is nonexistent when injurers do not know $h$ ex ante.

Now let us reconsider the case in which injurers know harm ex ante. We have (see the Appendix for the proof):

Proposition 4. Suppose that injurers know harm $h$ ex ante and that, after an accident, parties choose whether or not to spend $k$ to establish $h$ to courts.

(a) The optimal damages rule is defined as follows:

(i) if a party establishes $h$ and $h$ lies outside a specified interval $\left[h_{1}, h_{2}\right]$, damages equal $h$;

(ii) if a party establishes $h$ and $h$ lies inside the interval, or if both parties are silent, damages equal $\bar{h}_{c}$, the conditional mean of $h$ in $\left[h_{1}, h_{2}\right]$;

(iii) defendants reimburse plaintiffs for the cost $k$ of establishing $h$ when plaintiffs establish $h$ and $h$ lies outside the interval.

(b) Under the optimal damages rule, defendants will establish $h$ when $h<h_{1}$, both parties will be silent when $h$ lies in $\left[h_{1}, h_{2}\right]$, and plaintiffs will establish $h$ when $h>h_{2}$.

(c) If instead damages equal $h$ whenever a party establishes $h$ and plaintiffs are reimbursed for $k$ whenever they establish $h$, then more plaintiffs and more defendants will establish $h$ than under the optimal damages rule.

The central feature of the socially optimal rule is that parties are discouraged from demonstrating $h$ if $h$ lies in a midrange-the interval $\left[h_{1}, h_{2}\right]$-and otherwise they are led to establish $h$. The reason for this feature of the rule is in essence that the cost $k$ of establishing $h$ to courts is socially worthwhile to incur if and only if the resulting improvement in incentives is sufficiently large, something that will be true if and only if $h$ is relatively high or low.

The argument establishing that the rule is optimal may be sketched as follows (the proof is in the Appendix). Consider a dictator who not only can set damages but also can order individuals to report $h$ or to be silent. If it can be demonstrated that the rule of the proposition leads to the same outcome as the dictator can achieve, then the rule of the proposition must be optimal.

The dictator would set damages equal to $h$ when individuals establish $h$ because injurers will be induced to take optimal precautions if they pay 
the full costs of accidents, $h+k$. Note that this amount is what injurers will in fact pay if damages are $h$ and they establish $h$ and thus bear $k$, or if plaintiffs establish $h$ and injurers reimburse them for $k$. The dictator would also want damages to equal $\bar{h}_{c}$ when parties are silent, for $\bar{h}_{c}$ is the expected harm due to accidents caused by those who will be silent.

Finally, the dictator must choose the interval $\left[h_{1}, h_{2}\right]$ for which parties must be silent. The optimal $h_{1}$ is less than $\bar{h}_{c}-k$. To explain, consider a defendant who has caused harm $h$ equal to $\bar{h}_{c}-k$. His precautions will be $x^{*}\left(\bar{h}_{c}\right)$ if he will not report $h$, and his precautions will be the same if he will report $h$ (for then his damages will be $\bar{h}_{c}-k$ and he will spend $k$, so that his total expenses will be $\bar{h}_{c}$ ). Because his precautions will not be altered if he reports $h$, it must be best for the defendant to be ordered to be silent, saving resources of $k$; hence, the optimal $h_{1}$ is lower than $\bar{h}_{c}-k$. Similar reasoning explains why the optimal $h_{2}$ exceeds $\bar{h}_{c}$.

Now it is evident that under the damages rule of the proposition, with $\left[h_{1}, h_{2}\right]$ being the interval that the dictator would choose, individuals will behave as asserted in 4(b) and report $h$ if and only if $h$ lies outside the interval. (Thus, the outcome under the rule will indeed be that achievable by the dictator.) In particular, a defendant will want to reveal $h$ when it is less than $h_{1}$ even though this costs him $k$ because, as just discussed, $h_{1}<\bar{h}_{c}-k$. No party will want to spend $k$ to reveal $h$ if $h$ is in $\left[h_{1}, h_{2}\right]$, for then damages will be $\bar{h}_{c}$ regardless of the particular value of $h$ in the interval. And a plaintiff will always want to establish $h$ if $h>h_{2}$, for the plaintiff does not bear $k$.

With regard to excessive incentives to prove $h$ under the usual rule, as described in $4(c)$, observe that defendants would sometimes inefficiently spend to demonstrate $h$ if doing so would always result in damages of $h$ : because $h_{1}<\bar{h}_{c}-k$, defendants would pay $k$ to prove $h$ when $h$ is in $\left[h_{1}, \bar{h}_{c}-k\right)$. Also, plaintiffs obviously would sometimes inefficiently spend to establish $h$ if this would always result in their receiving damages of $h$ and being reimbursed for $k$, for then they would choose to establish $h$ whenever $h>\bar{h}_{c}{ }^{7}$ These problems of excessive incentives to demonstrate $h$ when doing so always affects damages are again caused by the fact that a party's motive to prove $h$ is unrelated to the associated incentive benefit.

Last, let us consider the case in which injurers choose whether or not to spend $c$ to learn about harm ex ante.

${ }^{7}$ We remark that plaintiffs might not have an excessive incentive to establish $h$ if they have to bear $k$ (which would not be optimal). The reason is that then defendants would be underdeterred. See the preceding version of this article: Louis Kaplow \& Steven Shavell, Accuracy in the Assessment of Damages (Working Paper No. 4287, Nat'l Bureau Econ. Res. 1993). 
Proposition 5. Suppose that injurers decide whether or not to learn harm $h$ ex ante and that, after an accident, parties choose whether or not to establish $h$ to courts.

(a) If it is not socially optimal for injurers to learn $h$ ex ante, then the optimal rule is that given in proposition 3 , and injurers will not be induced to learn $h$.

(b) If it is socially optimal for injurers to learn $h$ ex ante, then the optimal rule is that given in proposition 4 , and injurers will be induced to learn $h$.

Part 5(a) is obvious, for when damages are unaffected by revealing $h$, injurers will have no incentive ex ante to obtain information about $h$ or to spend ex post to establish it. Part $5(b)$ is clear, assuming that injurers are led to spend $c$ to learn $h$ when that is socially optimal, for then proposition 4 applies; the proof in the Appendix establishes that injurers will in fact be induced to spend $c$ when that is socially optimal, by reasoning analogous to that given for proposition 2.

\section{Extensions of the Analysis}

a) Generality of Conclusions. On reflection, it can be seen that our main conclusions apply more generally than to assessments of harm in accidents. Consider the conclusion that it is not socially desirable for resources to be spent informing courts of the magnitude of harm to the degree that harm was unknown to parties when they made their decisions. This conclusion is true also of any elements other than harm (such as facts about causation) unknown to parties when they made their decisions, under any legal rule in any area of law (for instance, under the negligence rule, or under a rule of contract damages). The reason, of course, is that making liability depend on elements not known to parties when they choose their actions cannot affect their behavior. Similarly, the other conclusions-about the effect of considering a factor in assessing damages on parties' incentives to learn about the factor ex ante, and about parties' excessive incentives to present information to courts about such a factor ex post-also hold more generally.

b) Settlement. We assumed in the model that all accidents resulted in trials, but if we were to allow for settlement, the qualitative nature of the conclusions would not be substantially altered. The reasons are twofold. First, the amounts paid in settlement tend to reflect the amounts that would be paid at trial, so that the incentive effects associated with amounts paid in settlement would resemble those associated with amounts paid at trial. Second, settlement, like trial, involves expense. Settlement is achieved through bargaining, voluntary exchange of infor- 
mation, and required disclosure of information (legal discovery). These are costly processes, and the more so when the information of relevance to the parties includes the actual magnitude of harm. ${ }^{8}$ Thus, the assumption in the model that parties incur a cost establishing harm to courts is mirrored by the added costs parties incur in the settlement process when courts base damages on accurate assessments of harm.

c) Risk Aversion and Insurance. Defendants' risk aversion is a factor disfavoring accuracy in the determination of harm, for a risk-averse defendant would prefer damages to be based on average harm than to bear the risk of actual harm. ${ }^{9}$ Conversely, plaintiffs' risk aversion favors accuracy in determination of harm because this assures compensation equal to losses. ${ }^{10}$ The availability of liability and first-party insurance, however, qualifies these points, for insurance coverage protects parties against risk.

It should also be noted that ownership of liability insurance reinforces our point that accurate assessment of harm may not much affect incentives. This is because the level of damages that are imposed in the particular instance will often matter little to a covered party, as his liability insurer will pay most or all of a court award.

d) The Effect of Injurers' Precautions on the Magnitude of Harm. We assumed in the model that an injurer's precautions affected only the likelihood of harm, but they might also influence the magnitude of harm by shifting downward the probability distribution of harm, as in Kathryn Spier's article. ${ }^{11}$ If that is so, then determining harm accurately has social value even when injurers do not have foreknowledge of a victim's type.

Specifically, suppose that courts do not determine actual harm and

$8: \rightarrow$ Lucian Bebchuk, Litigation and Settlement under Imperfect Information, 15 Rand J. Econ. 404 (1984), for a model of settlement with asymmetric information; : $\rightarrow$ Steven Shavell, Sharing of Information prior to Settlement or Litigation, 20 Rand J. Econ. 183 (1989), for a model in which information that is initially asymmetric is shared, or disclosed under discovery, and in which parties then frequently settle; and see $\varepsilon \rightarrow$ Bruce Hay, Civil Discovery: Its Effects and Optimal Scope, 23 J. Legal Stud. 481 (1994), on discovery. See, in addition, Kathryn Spier, Settlement Bargaining and the Design of Damage Awards, 10 J. L., Econ., \& Org. 84 (1994), for a model in which settlement becomes less likely when damages are based on accurate assessment of harm because this introduces an added element about which there can be asymmetric information.

${ }^{9}$ Uninsured risk-averse defendants would take lower precautions if damages equalled average harm rather than actual harm because the prospect of causing an accident involves lower risk-bearing costs. Such a reduction in precautions, however, would tend to be efficient because defendants' risk-bearing costs are social costs. Compare the discussion of defendants' prospective litigation costs in note 5 above.

${ }^{10}$ This statement applies if harm is monetary. If a component of harm (such as pain and suffering) is not monetary and does not affect the marginal utility of wealth, then risk-averse plaintiffs as well as defendants will prefer damages for that component to be based on average harm.

"See Spier, supra note 8. 
instead set damages equal to average harm. Then an injurer will know that the level of damages he will pay if an accident occurs will be a constant and will not be affected by his level of precautions-even though the distribution of harm will be lower the higher the level of precautions. Thus, injurers will have inadequate incentives to exercise precautions. (They will consider only the reduction in the probability of harm, but not the reduction in its magnitude, conditional on harm occurring.) By contrast, if courts accurately determine harm, injurers will know that the damages they pay, if accidents occur, will tend to be lower the greater the level of precautions they exercise, so injurers' incentives to take precautions will be optimal.

Note, however, that complete accuracy in the determination of harm is unnecessary: as long as courts' estimates are unbiased (given the injurers' level of precaution), incentives will be optimal. Suppose that courts' estimates of average harm are derived from a simple description of an accident (which would contain some information about the severity of injury). Then injurers who take greater precautions will expect to pay lower damages and thus will have appropriate incentives to take precautions. Greater accuracy will produce little if any additional benefit. ${ }^{12}$

e) Quality of Information. Although we assumed in the model that parties and the courts either possessed no information about harm-they knew only its probability density $f$-or possessed or acquired perfect information, the model can be interpreted more broadly. The "ignorant" state of knowledge can reflect real knowledge of harm: $f$ can describe the distribution of losses for any class of accidents, however narrow (such as mistaken releases of a specific pollutant into the atmosphere). At the same time, the "perfectly informed" state of knowledge can be less than perfect: $h$ can be reinterpreted as the mean of $h$ conditional on receipt of information about $h$ (such as the expected harm given the quantity of the pollutant that escaped), rather than as the true $h$ (the actual losses caused by the pollutant), without any effect on our analysis.

${ }_{12}$ Assume, for example, that there are two types of harm-minor injury and long-term disability - and that the magnitude of each type of harm varies among victims. Assume too that precautions not only reduce the probability of accidents but also make it less likely that harm will be of the more serious type. Finally, assume that injurers do not know, ex ante, anything about a particular potential victim. Now a court's immediate observation about an accident would include the type of harm, even though substantial additional expenditure might be required to determine a particular victim's harm. Using only the courts' initial estimate of harm would be sufficient to induce injurers to take optimal care (conditional on the information they possess ex ante): the damage award for each type of harm would be an unbiased estimate of harm given that type, and injurers only know the likelihood of each type of harm ex ante and the distribution of harms for each type, not the actual harm a particular victim would suffer. 
f) Courts' Information. We supposed for simplicity in the model that courts knew the probability density $f$ of harm at the outset. Another assumption, which is often realistic, is that courts do not know $f$, but when harm occurs, courts costlessly observe certain characteristics $z$ of the harm (for example, that a car of a certain type was demolished, that a person of a certain age was killed). The court then has two options. First, it may set damages equal to the mean harm, conditional on these characteristics, denoted by $\bar{h}(z)$. Second, it may hear evidence sufficient to allow it to determine the actual level of harm. This would require an expenditure of $k$.

Under this alternative assumption, the essential nature of our results would be unchanged. Where we had said that courts should set damages equal to $\bar{h}$, we now say that courts should set damages equal to $\bar{h}(z)$. Consider, for example, Proposition 1(a), dealing with the case where injurers do not know harm ex ante. Our claim now is that courts should not observe $h$ and should set damages equal to $\bar{h}(z)$. When this is done, the expected liability of injurers will again be $\bar{h}$ because the mean of $\bar{h}(z)$ equals $\bar{h}$. As a result, injurers will behave just as they would if damages were $\bar{h} \cdot{ }^{13}$

\section{Discussion}

The most immediate implications of our analysis can be well illustrated by considering the assessment of damages in a familiar and important context-automobile accident cases. Typically, a person who is injured in an automobile accident will gather and present evidence from a variety of sources, notably, from medical experts and from labor market specialists on forgone earnings. The defendant in response will seek to counter the plaintiff's assertions about his losses. The parties' expenditures are likely to be substantial because either will spend a dollar whenever it is expected to alter expected damages by more than a dollar in his favor. Thus, if the stakes in an accident were in the neighborhood of, say, $\$ 100,000$, each side might well expend $\$ 20,000$ contesting damages. ${ }^{14}$

Yet, as our analysis suggests, the prospect of such spending on proof of damages in automobile accidents is unlikely to influence drivers' incen-

${ }^{13}$ Consider also proposition $1(b)$, dealing with the case where injurers know harm ex ante. It is clear that, again, it will be optimal for the courts to observe $h$ if the cost $k$ is sufficiently low because, if the courts use $\bar{h}(z)$, injurers' incentives to take precautions will be less desirable than if courts use $h$. (However, injurers' incentives to take precautions will be superior when courts use $\bar{h}(z)$ than when courts use $\bar{h}$. Hence, $k$ must be lower now for it to be worthwhile for the courts to observe $h$ than in the model we studied.)

${ }_{14}$ Moreover, as we noted in Section III $b$ above, the parties might find it rational to spend significantly on establishing damages prior to settlement. 
tives toward safety. When choosing his level of precautions-how fast to drive, whether to go home by taxi after indulging-a driver cannot predict the particular level of harm he would cause in an accidentwhether the victim will be a bricklayer or a doctor, whether the victim's injuries will be minor, include broken bones, or result in death. Rather, a driver's prior knowledge will be only vague and approximate.

It follows that resources could be saved without compromising incentives by circumscribing the damage assessment process. Now in our analysis, we had assumed that courts know the average harm and use this as the quantum of damages. But it is unnecessary for courts to know average harm. At the outset of a case, courts will possess, essentially free of cost, a simple physical description of the plaintiff's injury-for instance, that a 35-year-old person suffered a broken leg. If damages are based on this description-if damages equal expected harm conditional on this description-then injurers' expected liability will equal average harm, so their incentives toward safety will be the same as if damages equal average harm. (This was the point that we discussed in Section III $f$.)

How can courts constrain the use of resources on damage assessment? One approach is for courts to impose restrictions on parties' litigation effort devoted to demonstrating damages. For example, the number of testifying experts could be limited. Such steps are quite plausible: judges are routinely involved in controlling the intensity of litigation, and recent procedural reforms are designed to curtail litigation efforts generally. As long as restrictions do not generate systematic biases in damage awards, they should not have any effect on drivers' incentives.

Another approach, and a radical departure from practice, is to eliminate the damage assessment process and replace it with the use of damage tables. ${ }^{15}$ Each entry in a damage table would equal the mean loss for a specific, physically described injury (such as for a broken arm). ${ }^{16}$ In such

${ }^{15}$ Although the use of damage tables would be a radical departure from practice in the courts, it is of course true that various statutory compensation systems, such as the workers' compensation system, employ damage tables to determine awards. For an analysis of the adequacy of workers' compensation damage payments, see Patricia M. Danzon, The Political Economy of Workers' Compensation: Lessons for Product Liability, 78 Am. Econ. Ass'n Papers \& Proc. 305 (1988).

${ }^{16}$ If the table were biased, injurers' incentives would not be optimal. Any biases would have to be compared to those arising with jury awards that may reflect sympathies for parties and other extraneous factors. Indeed, some have advocated damage tables in large part because of a belief that the tables would be less biased than jury awards are today. See, for exam $1 \rightarrow$ Albert W. Alschuler, Mediation with a Mugger: The Shortage of Adjudicative Services and the Need for a Two-Tier Trial System in Civil Cases, 99 Harv. L. Rev. 1808 (1986); and Frederick S. Levin, Pain and Suffering Guidelines: A Cure for Damages Measurement "Anomie," 22 Univ. Mich. J. L. Reform 303 (1989). For a discussion of methods for constructing damage schedules and of difficulties that may be encountered in so doing, see Randall R. Bovbjerg, Frank A. Sloan, \& James F. Blumstein, Valuing Life and Limb in Tort: Scheduling "Pain and Suffering," 83 Nw. U. L. Rev. 908 (1989). 
a system, it is apparent that, as just stated, a driver's incentives would indeed be no different from what they are in today's regime: a driver would say to himself, "I cannot forecast the kind of accident and the injuries that I may cause, but I do know that if I am found liable, damages will be based on a physical description of the injuries together with a table giving average losses for those injuries." It is plain, we think, that this driver would behave in much the same way he would if he anticipated that losses would be calculated to the last penny. ${ }^{17}$

The potential appeal that we see in restricting litigation effort or in using damage tables is what others have long stressed as their virtue: the achievement of cost savings. But prior discussions have largely ignored the question of whether changing the process of damage assessment might detrimentally influence injurers' behavior. ${ }^{18}$ What we add to prior work, therefore, is the point that simplified damage assessment would not distort injurers' behavior when, as we believe to be true in the context of driving, injurers' foreknowledge of harm is ordinarily less precise than what courts would immediately observe about harm after an accident. ${ }^{19}$

We hasten to say, however, that in many contexts substantial regulation of parties' efforts to establish damages or the use of damage tables will be undesirable because injurers' ex ante perceptions of harm will be more accurate than courts' initial estimates. Consider a situation where a builder might cause a delay in completing a commercial building. Here the builder would often have a fair understanding of the cost of delay (or could inquire about it). Damage tables based on general averages of loss for construction delay would tend to be less accurate than the builder's prior estimate. Accordingly, the use of tables, or of only cursorily considered losses, to arrive at damages would influence contract breach behavior relative to a reasonably full consideration of losses. For example, when losses are known to be higher than in the tables, breach would be too frequent. (To be sure, such inefficient breach is often avoidable through the use of liquidated damage provisions or through bargaining before breach.)

${ }^{17}$ For qualifications concerning litigation costs and risk aversion, see notes 5 and 9 above.

${ }^{18}$ For example, the commentary to the recently implemented amendments to the Federal Rules of Civil Procedure does not discuss the effect of litigation on injurers' behavior, either in suggesting the rationale for various limits or in offering guidance to judges in exercising their discretion. The literature on damage tables is somewhat more attentive to injurers' behavior. It sometimes suggests that behavior would be improved because the tables would more accurately measure harm than present jury awards; see note 16 supra. This contrasts with our point about damage tables: we assume that damage tables will be less accurate than present jury awards and emphasize that, even so, injurers' behavior will not be detrimentally affected.

${ }^{19}$ Our analysis also adds to the literature because of its relevance to the design of damage tables: it raises questions about the social value of highly detailed tables and of permitting parties to prove that their losses are different from those in the tables. 
Thus, there are circumstances where the magnitude of losses can be well anticipated by potential injurers and, consequently, where our analysis implies that accuracy in estimating damages would improve incentives. Nonetheless, the reader will recall that we showed that parties may still have an excessive incentive to spend to show damages, so that some restrictions on their efforts may be warranted. ${ }^{20}$

Last, we should say that constraining the ability of litigants to prove damages, whether through use of tables or through limitations on their expenditures, is likely to be met with the objection that victims will be compensated less accurately. It is true, as we noted in Section III $c$, that imprecise matching of damage payments to victims' losses represents a social cost when victims are risk-averse and are not insured. ${ }^{21}$ But it can be demonstrated that, even if the sole function of liability were to compensate uninsured, risk-averse victims, their incentives to establish harm in adjudication would be excessive. ${ }^{22}$ Moreover, the relevance of victims' risk aversion is attenuated by the fact that ownership of insurance is widespread. ${ }^{23}$

\section{APPENDIX}

Proof of Proposition 1. (a) If courts do not observe $h$, then a single level of damages $d$ applies to all injurers, and each injurer chooses $x$ to minimize

$$
x+p(x) d,
$$

so all choose $x^{*}(d)$. Social costs are given by

$$
\int_{0}^{\infty}\left[x^{*}(d)+p\left(x^{*}(d)\right) h\right] f(h) d h=x^{*}(d)+p\left(x^{*}(d)\right) \bar{h} .
$$

${ }^{20}$ This is always true with regard to proof beyond what injurers could have anticipated, and our analysis demonstrates that it may be true even when injurers accurately anticipate harm.

${ }^{21} \mathrm{We}$ also noted that more accurate compensation of victims means that more risk is imposed on injurers, which lowers social welfare to the extent that injurers are risk-averse and do not possess liability insurance.

${ }^{22}$ This is because, after a victim has suffered a loss, his incentive to spend to demonstrate the level of his losses is quite strong: he will spend up to a dollar to increase his coverage by a dollar. (And defendants' incentives to reduce liability are similar.) Yet such post-loss expenditure exceeds that which can be justified on grounds of risk reduction. See, generally, Louis Kaplow, Optimal Insurance Contracts When Establishing the Amount of Losses Is Costly, 19 Geneva Papers on Risk \& Ins. Theory 139 (1994), on excessive incentives of insureds to establish their losses to an insurer.

${ }^{23}$ An implication of the discussion in this paragraph is that accuracy in estimating loss is more important for purposes of insurance than for the liability system (when injurers lack precise ex ante information about loss). Yet the liability system employs more expensive means of assessing damages than is typical in consensual first-party insurance contracts (where simple appraisal schemes and binding arbitration are common). 
As (A2) is minimized when $d=\bar{h}, \bar{h}$ is the optimal level of damages, and social costs are

$$
x^{*}(\bar{h})+p\left(x^{*}(\bar{h})\right) \bar{h} .
$$

If courts observe $h$ and $d=h$ (which will be shown to be an optimal choice of $d$ ), then because injurers do not know what $h$ will be, they will choose $x$ to minimize

$$
x+p(x) \int_{0}^{\infty}(h+k) f(h) d h=x+p(x)(\bar{h}+k),
$$

so they will choose $x^{*}(\bar{h}+k)$, and social costs will be

$$
x^{*}(\bar{h}+k)+p\left(x^{*}(\bar{h}+k)\right)(\bar{h}+k) \text {. }
$$

It follows also that $d=h$ must be an optimum when $h$ is observed, for when injurers do not know $h$ ex ante and thus all choose the same $x$, (A4) gives social costs, which are minimized when $x$ is $x^{*}(\bar{h}+k) \cdot{ }^{24}$ Because (A5) exceeds (A3) for any positive $k$, we have established $1(a)$.

(b) In this case, if courts do not observe $h$, injurers will behave as they did in the previous case, so optimal damages will again be $\bar{h}$, and (A3) will again give social costs.

If courts observe $h$ and $d=h$ (which will be shown to be optimal), then a party of type $h$ minimizes $x+p(x)(h+k)$ because he will pay damages of $h$ and bear costs of $k$ if there is an accident. Hence, he will select $x^{*}(h+k)$. Because this choice of $x$ is optimal given the assumption that $h$ is observed, it is optimal for damages to equal $h$. Social costs in this situation are

$$
\int_{0}^{\infty}\left[x^{*}(h+k)+p\left(x^{*}(h+k)\right)(h+k)\right] f(h) d h .
$$

The difference in social costs between the situations where $h$ is not observed and when it is observed is (A3) minus (A6):

$$
x^{*}(\bar{h})+p\left(x^{*}(\bar{h})\right) \bar{h}-\int_{0}^{\infty}\left[x^{*}(h+k)+p\left(x^{*}(h+k)\right)(h+k)\right] f(h) d h .
$$

When $k=0$, (A7) equals

$$
\int_{0}^{\infty}\left\{\left[x^{*}(\bar{h})+p\left(x^{*}(\bar{h})\right) h\right]-\left[x^{*}(h)+p\left(x^{*}(h)\right) h\right]\right\} f(h) d h,
$$

which is positive because for every $h$ other than $\bar{h}, x^{*}(h)$ differs from $x^{*}(\bar{h})$ - the optimal level of precaution exceeds (is less than) $x^{*}(\bar{h})$ when $h$ exceeds (is less than) $\bar{h}$. In addition, it is clear that (A7) is decreasing in $k$ because, as $k$ increases, (A6) rises; also, (A7) is negative for all $k$ that are sufficiently large. ${ }^{25}$ It follows that there is a critical $k^{*}>0$ such that $k<k^{*}$ implies that it is socially desirable to observe $h$ and such that $k>k^{*}$ implies that it is not socially worthwhile to observe $h$.

Proof of Proposition 2. We need to complete the proof of part 2(b). To deter-

${ }^{24}$ Of course, $d=\bar{h}$ for all $h$ is also an optimum.

${ }^{25}$ If $k \geq \bar{h}$, then the integrand in (A7) exceeds $x^{*}(\bar{h})+p\left(x^{*}(\bar{h})\right) \bar{h}$ for all positive $h$, so (A7) must be negative for such $k$. 
mine whether it is socially optimal for injurers to learn $h$, note that, if injurers do not observe $h$ ex ante, minimum social cost is (A3) by proposition 1(a), and if injurers do observe $h$ ex ante, minimum social cost is (A6) plus $c$, by proposition $1(b)$. Hence, it is socially optimal for injurers to learn $h$ if and only if

$$
\begin{aligned}
x^{*}(\bar{h})+p\left(x^{*}(\bar{h})\right) \bar{h}-\{c & +\int_{0}^{\infty}\left[x^{*}(h+k)\right. \\
& \left.\left.+p\left(x^{*}(h+k)\right)(h+k)\right] f(h) d h\right\}>0 .
\end{aligned}
$$

(This will hold if $c$ and $k$ are sufficiently low.)

We need to show that when (A9) holds, injurers will be induced to learn $h$ if $d=h$. If an injurer does not learn $h$ ex ante, he will choose $x$ to minimize

$$
x+p(x) \int_{0}^{\infty}(h+k) f(h) d h=x+p(x)(\bar{h}+k),
$$

so that his costs will be $x^{*}(\bar{h}+k)+p\left(x^{*}(\bar{h}+k)\right)(\bar{h}+k)$. If an injurer does learn $h$ ex ante, his costs will be (A6) plus $c$. Hence, an injurer will be led to learn $h$ if

$$
\begin{aligned}
c \leq & {\left[x^{*}(\bar{h}+k)+p\left(x^{*}(\bar{h}+k)\right)(\bar{h}+k)\right] } \\
& -\int_{0}^{\infty}\left[x^{*}(h+k)+p\left(x^{*}(h+k)\right)(h+k)\right] f(h) d h .
\end{aligned}
$$

We want to show that (A9) implies (A11). But this follows because

$$
x^{*}(\bar{h})+p\left(x^{*}(\bar{h})\right) \bar{h}<x^{*}(\bar{h}+k)+p\left(x^{*}(\bar{h}+k)\right)(\bar{h}+k) .
$$

Proof of Proposition 3. The remarks in the text constitute a proof.

Proof of Proposition 4. To prove that the optimal rule is as claimed, consider the problem of a dictator whose goal is to minimize social costs and who can command parties whether or not to spend $k$ to reveal $h$ to courts (but who cannot command levels of precaution). The level of social costs achievable by the dictator will clearly be at least as low as under the optimal rule. We will determine the optimal solution to the dictator's problem and then show that this solution can be sustained under the rule described in the proposition. Thus, that rule must be optimal.

Let $S$ be the optimal set of $h$ where individuals are ordered by the dictator to be silent about $h$, and let $R$ be the optimal set of $h$ where individuals are made to reveal $h$. We assume for convenience that each set is a union of nondegenerate intervals. ${ }^{26}$ It is evident (by the logic in proposition $1(a)$ ) that for $h$ in $S$, the optimal $x$ for defendants to choose is $x^{*}\left(\bar{h}_{c}\right)$, where $\bar{h}_{c}$ is the conditional mean of $h$ in $S$; this $x$ will be chosen if $d=\bar{h}_{c}$. It is apparent also that for $h$ in $R$, it is optimal for defendants to choose $x^{*}(h+k)$; this will occur if a defendant's expenses are $h+k$, that is, if $d=h$ and defendants bear $k$.

Let us assume provisionally that $S$ is not empty (we will prove this below), so

${ }^{26}$ If we did not make this assumption, then in particular we would have to concern ourselves with the fact that the optimal $R$ and $S$ are not unique with respect to isolated points; any number of isolated points can be assigned to either $R$ or $S$ without affecting social cost, as the integral over isolated points is zero. 
that $\bar{h}_{c}$ exists, and let us characterize the form of $S$. Let $h_{1}$ be the supremum of $h$ in $R$ that are less than $\bar{h}_{c}$. We claim that any $h<h_{1}$ is in $R$. Now for any $h$ in $R$, we know that

$$
x^{*}(h+k)+p\left(x^{*}(h+k)\right)(h+k) \leq x^{*}\left(\bar{h}_{c}\right)+p\left(x^{*}\left(\bar{h}_{c}\right)\right) h .
$$

That is, expected costs are lower (or equal) if a party reports harm than if he does not. It follows that

$$
x^{*}\left(h_{1}+k\right)+p\left(x^{*}\left(h_{1}+k\right)\right)\left(h_{1}+k\right) \leq x^{*}\left(\bar{h}_{c}\right)+p\left(x^{*}\left(\bar{h}_{c}\right)\right) h_{1} .
$$

Inequality (A13) implies that $h_{1}+k \leq \bar{h}_{c}$ : otherwise,

$$
\begin{aligned}
x^{*}\left(h_{1}+k\right)+p\left(x^{*}\left(h_{1}+k\right)\right)\left(h_{1}+k\right) & >x^{*}\left(\bar{h}_{c}\right)+p\left(x^{*}\left(\bar{h}_{c}\right)\right) \bar{h}_{c} \\
& \geq x^{*}\left(\bar{h}_{c}\right)+p\left(x^{*}\left(\bar{h}_{c}\right)\right) h_{1},
\end{aligned}
$$

which contradicts (A13). Hence, $p\left(x^{*}\left(h_{1}+k\right)\right) \geq p\left(x^{*}\left(\bar{h}_{c}\right)\right)$, so that

$$
p\left(x^{*}\left(h_{1}+k\right)\right)\left(h_{1}-h\right) \geq p\left(x^{*}\left(\bar{h}_{c}\right)\right)\left(h_{1}-h\right)
$$

for $h<h_{1}$. The latter inequality and (A13) imply that, for $h<h_{1}$,

$$
x^{*}\left(h_{1}+k\right)+p\left(x^{*}\left(h_{1}+k\right)\right)(h+k) \leq x^{*}\left(\bar{h}_{c}\right)+p\left(x^{*}\left(\bar{h}_{c}\right)\right) h .
$$

But, for $h<h_{1}$,

$$
x^{*}(h+k)+p\left(x^{*}(h+k)\right)(h+k)<x^{*}\left(h_{1}+k\right)+p\left(x^{*}\left(h_{1}+k\right)\right)(h+k) .
$$

This and (A15) imply

$$
x^{*}(h+k)+p\left(x^{*}(h+k)\right)(h+k)<x^{*}\left(\bar{h}_{c}\right)+p\left(x^{*}\left(\bar{h}_{c}\right)\right) h .
$$

Hence, for $h<h_{1}$, it is better for a party to report $h$ than not; $h$ is in $R$, as claimed. A parallel argument shows that, if $h_{2}$ is defined as the infimum of $h$ in $R$ that are greater than $\bar{h}_{c}$, then all $h>h_{2}$ are in $R$. Thus, we know that $S$ consists of the interval $\left[h_{1}, h_{2}\right]$.

Because $S$ is optimal, $h_{1}$ and $h_{2}$ must be selected to minimize social costs. Social costs as a function of $h_{1}$ and $h_{2}$ are given by

$$
\begin{gathered}
\int_{0}^{h_{1}}\left[x^{*}(h+k)+p\left(x^{*}(h+k)\right)(h+k)\right] f(h) d h \\
+\int_{h_{1}}^{h_{2}}\left[x^{*}\left(\bar{h}_{c}\right)+p\left(x^{*}\left(\bar{h}_{c}\right)\right) h\right] f(h) d h \\
+\int_{h_{2}}^{\infty}\left[x^{*}(h+k)+p\left(x^{*}(h+k)\right)(h+k)\right] f(h) d h .
\end{gathered}
$$

The derivative of (A18) with respect to $h_{1}$ is

$$
\left\{\left[x^{*}\left(h_{1}+k\right)+p\left(x^{*}\left(h_{1}+k\right)\right)\left(h_{1}+k\right)\right]-\left[x^{*}\left(\bar{h}_{c}\right)+p\left(x^{*}\left(\bar{h}_{c}\right)\right) h_{1}\right]\right\} f\left(h_{1}\right) .
$$

For $h_{1} \geq \bar{h}_{c}-k$, (A19) is negative, as demonstrated in (A14). Therefore, $h_{1}<\bar{h}_{c}-k$, assuming such an $h_{1}$ is feasible (otherwise, $h_{1}=0$ ). The derivative of (A18) with respect to $h_{2}$ is

$$
\left\{\left[x^{*}\left(\bar{h}_{c}\right)+p\left(x^{*}\left(\bar{h}_{c}\right)\right) h_{2}\right]-\left[x^{*}\left(h_{2}+k\right)+p\left(x^{*}\left(h_{2}+k\right)\right)\left(h_{2}+k\right)\right]\right\} f\left(h_{2}\right) .
$$


At $h_{2}=\bar{h}_{c}$, this is negative, because

$$
x^{*}\left(\bar{h}_{c}\right)+p\left(x^{*}\left(\bar{h}_{c}\right)\right) \bar{h}_{c}<x^{*}\left(\bar{h}_{c}+k\right)+p\left(x^{*}\left(\bar{h}_{c}+k\right)\right)\left(\bar{h}_{c}+k\right) .
$$

Hence, $h_{2}>\bar{h}_{c}$.

It remains to show that $S$ is not empty. If this is not true-that is, if $R$ equals the set of all positive $h$-select any positive $h$ and denote it by $h_{1}$. Then social costs will be lowered if parties are silent and pay $h_{1}$ whenever $h$ falls in some small nondegenerate interval $\left[h_{1}, h_{2}\right] .{ }^{27}$ This contradicts the supposed optimality of $R$.

We have now proved that the optimal rule for the dictator is characterized as follows: there is an interval $\left[h_{1}, h_{2}\right]$, where $h_{1}<\bar{h}_{c}-k$ and $h_{2}>\bar{h}_{c}$, on which parties do not report $h$ and pay damages of $\bar{h}_{c}$; outside the interval, parties report $h$, pay damages of $h$, and defendants bear $k$. It is clear (and was explained after the proposition) that under the rule of the proposition, with this $\left[h_{1}, h_{2}\right]$, parties behave as the dictator would want. Thus, as stated at the outset, because the rule in the proposition implements the dictator's optimal scheme, the rule in the proposition must be optimal.

Proof of Proposition 5. From the notes following the proposition, it is clear that it suffices to show that if it is optimal for injurers to spend $c$ to learn $h$ ex ante, they will be led to do this under the rule specified in proposition 4 .

If injurers do not learn $h$ ex ante, minimum social costs will be (A3), and if injurers do learn $h$, minimum social costs will be

$$
\begin{gathered}
\int_{0}^{h_{1}}\left[x^{*}(h+k)+p\left(x^{*}(h+k)\right)(h+k)\right] f(h) d h \\
+\int_{h_{1}}^{h_{2}}\left[x^{*}\left(\bar{h}_{c}\right)+p\left(x^{*}\left(\bar{h}_{c}\right)\right) h\right] f(h) d h \\
+\int_{h_{2}}^{\infty}\left[x^{*}(h+k)+p\left(x^{*}(h+k)\right)(h+k)\right] f(h) d h+c,
\end{gathered}
$$

where $\left[h_{1}, h_{2}\right]$ is the optimal interval. Thus, it is socially desirable for injurers to learn $h$ if (A22) is less than (A3).

Now let us show that when (A22) is less than (A3), injurers will in fact learn $h$, provided that the rule in proposition 4 applies. Given that this rule applies, if injurers do not learn $h$, they will choose $x$ to minimize

$$
\begin{gathered}
\int_{0}^{h_{1}}[x+p(x)(h+k)] f(h) d h+\int_{h_{1}}^{h_{2}}[x+p(x) h] f(h) d h \\
+\int_{h_{2}}^{\infty}[x+p(x)(h+k)] f(h) d h .
\end{gathered}
$$

If injurers do learn $h$, their expected costs will be given by (A22). Thus, they will learn $h$ if (A22) is less than (A23). But (A23) exceeds (A3) because (A3) is the minimum value of

${ }^{27}$ Social costs will be given by (A18), but with the integrand in the second integral $x^{*}\left(h_{1}\right)+p\left(x^{*}\left(h_{1}\right)\right) h$. The derivative of this with respect to $h_{2}$ is $\left\{\left[x^{*}\left(h_{1}\right)+p\left(x^{*}\left(h_{1}\right)\right) h_{2}\right]-\right.$ $\left.\left[x^{*}\left(h_{2}+k\right)+p\left(x^{*}\left(h_{2}+k\right)\right)\left(h_{2}+k\right)\right]\right\}$. At $h_{2}=h_{1}$, the derivative is negative, so that social costs are lower for some $h_{2}>h_{1}$. 


$$
\int_{0}^{\infty}[x+p(x) h] f(h) d h .
$$

Hence, when (A22) is less than (A3), (A22) will also be less than (A23), and injurers will decide to learn $h$ ex ante.

\section{BIBLIOGRAPHY}

$\rightarrow$ Alschuler, Albert W. "Mediation with a Mugger: The Shortage of Adjudicative Services and the Need for a Two-Tier Trial System in Civil Cases." Harvard Law Review 99 (1986): 1808-59.

$\rightarrow$ Bebchuk, Lucian Arye. "Litigation and Settlement under Imperfect Information." Rand Journal of Economics 15 (1984): 404-15.

Bovbjerg, Randall R.; Sloan, Frank A.; and Blumstein, James F. "Valuing Life and Limb in Tort: Scheduling 'Pain and Suffering.'" Northwestern University Law Review 83 (1989): 908-76.

$\rightarrow$ Brown, John Prather. "Toward an Economic Theory of Liability." Journal of Legal Studies 2 (1973): 323-49.

$\rightarrow$ Craswell, Richard, and Calfee, John E. "Deterrence and Uncertain Legal Standards." Journal of Law, Economics, and Organization 2 (1986): 279-303.

$\rightarrow$ Danzon, Patricia M. "The Political Economy of Workers' Compensation: Lessons for Product Liability." American Economic Association Papers and Proceedings 78 (1988): 305-10.

$\rightarrow$ Hay, Bruce L. "Civil Discovery: Its Effects and Optimal Scope." Journal of Legal Studies 23 (1994): 481-515.

$\rightarrow$ Kaplow, Louis. "The Value of Accuracy in Adjudication: An Economic Analysis." Journal of Legal Studies 23 (1994): 307-401.

Kaplow, Louis. "Optimal Insurance Contracts When Establishing the Amount of Losses Is Costly." Geneva Papers on Risk and Insurance Theory 19 (1994): $139-52$.

$\rightarrow$ Kaplow, Louis. "A Model of the Optimal Complexity of Legal Rules." Journal of Law, Economics, and Organization 11 (1995): 150-63.

$\rightarrow$ Kaplow, Louis, and Shavell, Steven. "Private versus Socially Optimal Provision of Ex Ante Legal Advice." Journal of Law, Economics, and Organization 8 (1992): 306-20.

Kaplow, Louis, and Shavell, Steven. "Accuracy in the Assessment of Damages." Working Paper No. 4287. Cambridge, Mass.: National Bureau of Economic Research, 1993.

$\rightarrow$ Kaplow, Louis, and Shavell, Steven. "Accuracy in the Determination of Liability." Journal of Law and Economics 37 (1994): 1-15.

Landes, William M., and Posner, Richard A. The Economic Structure of Tort Law. Cambridge, Mass.: Harvard University Press, 1987.

Levin, Frederick S. "Pain and Suffering Guidelines: A Cure for Damages Measurement 'Anomie.' " University of Michigan Journal of Law Reform 22 (1989): 303-32.

$\rightarrow$ Polinsky, A. Mitchell, and Shavell, Steven. "Legal Error, Litigation, and the 
Incentive to Obey the Law." Journal of Law, Economics, and Organization 5 (1989): 99-108.

$\rightarrow$ Posner, Richard A. "An Economic Approach to Legal Procedure and Judicial Administration." Journal of Legal Studies 2 (1973): 399-458.

Png, I. P. L. "Optimal Subsidies and Damages in the Presence of Judicial Error." International Review of Law and Economics 6 (1986): 101-5.

$\rightarrow$ Rubinfeld, Daniel L., and Sappington, David E. M. "Efficient Awards and Standards of Proof in Judicial Proceedings." Rand Journal of Economics 18 (1987): 308-15.

Shavell, Steven. Economic Analysis of Accident Law. Cambridge, Mass.: Harvard University Press, 1987.

$\rightarrow$ Shavell, Steven. "Sharing of Information prior to Settlement or Litigation." Rand Journal of Economics 20 (1989): 183-95.

$\rightarrow$ Spier, Kathryn. "Settlement Bargaining and the Design of Damage Awards." Journal of Law, Economics, and Organization 10 (1994): 84-95. 